\title{
Change in spousal violence before and during the COVID-19 pandemic in Egypt
}

\author{
EMAN ESMAT TOSSON ${ }^{\mathrm{A}, \mathrm{B}, \mathrm{D}-\mathrm{F}}$, RABAB ATTA SAUDIA-F \\ ORCID ID: 0000-0001-6553-4861 \\ Family Medicine Department, Faculty of Medicine, Suez Canal University, Ismailia City, Egypt
}

A - Study Design, B - Data Collection, C - Statistical Analysis, D - Data Interpretation, E - Manuscript Preparation, F - Literature Search, G - Funds Collection

Summary Background. Egypt has been severely affected by the Coronavirus Disease (COVID-19) since March 2020. To slow the spread of Coronavirus (COVID-19), measures such as social isolation, travel restrictions and stay-at-home are dramatically increasing the risk of domestic violence.

Objectives. This study aimed to assess the prevalence of various forms of spousal violence against women and explore whether the prevalence of domestic violence changed during the COVID-19 pandemic compared to its prevalence one year before.

Material and methods. Using a web-based cross-sectional survey, we collected data from 2,190 Egyptian women using an anonymous online questionnaire. The survey was conducted through a link shared on social networks from 20 May 2020 to 20 June 2020. A semi-structured questionnaire was used to collect data on socio-demographic variables and details of domestic violence.

Results. The overall prevalence of spousal violence during the COVID-19 pandemic was $43.2 \%$, with physical violence being the most common type. $52.75 \%$ of abused women did not disclose the abuse or seek assistance although suffering. The findings revealed a significant increase in the rate of the overall spousal violence and all forms of violence (emotional, physical and sexual violence) during the COVID-19 pandemic quarantine $(p<0.05)$. Age, duration of marriage, educational status of subjects and their spouses, residence, spouse with substance-abuse, depression, and insomnia were reported as significant predictors of domestic violence among the Egyptian women.

Conclusions. The prevalence of domestic violence in Egypt is considerably high and significantly increased during COVID-19 pandemic. Key words: coronavirus, Egypt, domestic violence, prevalence.

Tosson EE, Saudi RA. Change in spousal violence before and during the COVID-19 pandemic in Egypt. Fam Med Prim Care Rev 2021 23(4): 481-487, doi: https://doi.org/10.5114/fmpcr.2020.100447.

\section{Background}

The COVID-19 pandemic, also known as the coronavirus pandemic, is caused by SARS-CoV-2, an acute respiratory syndrome known as coronavirus 2 , which has caused significant destruction worldwide [1]. The outbreak was first identified in December 2019 in Wuhan, China [2]. This first outbreak of new coronavirus was declared as a public health emergency of international concern by the World Health Organization on 30 January and a global pandemic on 11 March 2020 [3].

Unfortunately, there is no appropriate treatment for COVID-19 other than protective measures such as social isolation, travel restrictions and stay-at-home orders, which have been introduced to eliminate the spread of SARS-CoV-2 [4]. While all countries carry out stay-at-home orders differently, in most cases, people are required to leave for vital activities (e.g. food or medical treatment) or being a worker in critical industries (e.g. health care). Although such interventions may be successful in controlling the spread and transmission of the disease, they have a profound negative impact on society, leading to social, financial and psychological consequences. Furthermore, the temporary shutdown of non-essential business has resulted in unemployment and economic strain [5].

The quarantine conditions for persons whose lives are affected by domestic violence (DV) are associated with a disastrous environment [6]. With social isolation, widespread organisational closures linked to COVID-19, stress and depression, both risk factors for family violence and conflict are likely to be further aggravated by such issues as unemployment, decreased income, limited resources and insufficient social assistance [7].
Domestic violence is a global epidemic, with an estimated $30 \%$ of women experiencing physical and/or sexual violence during their lifetime from an intimate partner [8]. Domestic violence (DV) is defined as violence perpetrated towards another adult by a family member or an intimate partner. Much of the international evidence currently available focuses on intimate partner violence (IPV), which is a subset of domestic violence [9].

The World Health Organization (WHO) declared domestic violence to be an "epidemic of public health». More than a third of women globally continue to suffer from domestic violence [10]. The WHO estimated that $37 \%$ of women have experienced physical or sexual IPV in the Eastern Mediterranean region (EMR) [11]. Furthermore, 30.3\% of Egyptian women who were ever married witnessed spousal abuse, $18.6 \%$ in the last year alone [12]. Although data on DV incidence and prevalence are scarce in Middle Eastern regions, current evidence suggests that many women are affected [13]. The 2013 WHO study showed a prevalence of DV in the Eastern Mediterranean region and the Southeast Asian region, which was especially high [14].

Within the Middle East, the social and cultural stigmas surrounding seeking professional mental health services are significant barriers to getting help for the effects of psychological issues [15]. Other barriers include fear of further violence, loss of support, loss of relationships, concern for a child, unsafe immigration status, disruption of family life and cultural networks and the involvement of child protection services [16].

As family physicians are usually the first points of contact with women within the health care system, identification of victims of domestic violence and offering them help is important. 
Because women may not voluntarily disclose partner violence, as it is a sensitive issue, innovative approaches such as opportunistic screening for domestic violence by physicians at health facilities with a valid simplified tool will be useful, and this should be implemented at the level of primary health care centres.

Considering the important role of family physicians in domestic violence identification and due to lack of accurate data on domestic violence prevalence during COVID-19 quarantine in Egypt this research aimed to assess change in spousal violence before and during COVID-19 pandemic in Egypt.

\section{Objectives}

This study aimed to assess the prevalence of various types of domestic violence against women by their partners during the COVID-19 pandemic quarantine and examine whether the prevalence of domestic violence changed during the COVID-19 pandemic compared to its prevalence one year before.

\section{Material and methods}

\section{Study design and participants}

This is a cross-sectional observational study using an anonymous online questionnaire. A self-administered questionnaire link was broadcast through social networks. The study was conducted from 20 May 2020 to 20 June 2020. Egyptian women who fulfilled the inclusion criteria and agreed to participate in the study were included through the convenience and snowball sampling technique $(2,190$ females $)$.

\section{Inclusion and exclusion criteria}

Egyptian females aged 18 years or more, who had been ever married, able to understand and read Arabic, who often use social networks, and who were willing to give informed consent were included. Females living in Egypt from other nationalities and those who refused to take part in the study were excluded.

\section{Study tools}

The semi-structured questionnaire consisted of three components:

1. Socio-demographic characteristics including: age, education, occupation, marriage duration, consanguinity, number of children, residency, type of house, substanceabusing husbands, monthly income. Health status including: self-reported general health status, history of chronic diseases, frequency of doctor visits during the last year, depression (assessed using the patient health questionnaire-2 (PHQ-2); if the score is 3 or greater, a depressive disorder is likely) and history of insomnia affecting daily life.

2. The Norvold Domestic Abuse Questionnaire (NORAQ): This validated instrument includes 13 descriptive questions measuring three forms of abuse: emotional, physical and sexual abuse, which was developed in a Nordic multi-centre study among gynaecological patients [17]. The response categories were yes or no for each form and abuse level. These were categorised into mild, moderate and severe according to level of severity reported. In this study, the two items addressing 'mild sexual abuse with no genital contact' and 'mild humiliating sexual abuse' were combined into one category of 'mild sexual abuse'. The degree of current suffering was assessed using a visual analogue scale (0-10) and was categorised as no suffering $(0)$, moderate suffering $(1-5)$ and severe current suffering $(\geq 6)$. Women were defined as having experienced any abuse if they an- swered yes to at least one of the sexual, emotional or physical abuse questions. A validated Arabic version of (NORAQ) was used to study the prevalence of spousal violence against Egyptian women. The Arabic NORAQ content validity index was 0.90 , while the alpha reliability coefficients were 0.75 for the total scale [18].

3. The third part of the questionnaire examined the disclosure and women's attempts to seek assistance.

\section{Validation and pilot study}

We pre-tested the questionnaire through conducting a pilot survey on 30 women. The questionnaire was refined based on the feedback we obtained. The questionnaire had good internal consistency (Cronbach's alpha $=0.72$ ).

\section{Data collection}

Data was collected through a semi-structured online questionnaire using Google Forms. The questionnaire link was sent through emails, Facebook groups, WhatsApp groups and other social media. The participants were encouraged to roll out the survey to more women. On receiving and clicking the link, the participants were referred to information about the research and informed consent. After they agreed to take the survey, they filled in the demographic details. A set of several questions appeared consecutively for the participants to answer. This study gathered information about spousal violence against women in two time frames: during the current COVID-19 pandemic quarantine and 12 months before the current pandemic.

\section{Outcome variables}

Three forms of domestic violence (emotional, physical and sexual violence).

\section{Statistical analysis}

Statistical Package for Social Sciences (SPSS) version 20 was used for data analysis. Descriptive characteristics were outlined as frequencies and percentages for categorical variables. McNamara's test was used to identify the difference between individual responses before and after the COVID-19 pandemic on dichotomous dependent variables. Binary logistic regression was used to assess the predictors of domestic violence. A $p$-value of $<0.05$ was considered statistically significant.

\section{Research ethics}

All procedures performed in the study were in accordance with the ethical standards of the institutional research committee and with the 1964 Helsinki Declaration and its later amendments. Ethical approval for the study was obtained from the Ethics Committee of Faculty of Medicine. Suez Canal University approved the study (Code 4281\#). Confidentiality and anonymity were assured. Informed consent was obtained from all participants included in the study.

\section{Results}

A total of 2,190 married Egyptian women participated in the study, and most of the sample $(1,750$ individuals $(79.9 \%))$ were in the age range of 18 to 44 years. Nearly half $(1,083(49.5 \%))$ of the women were married for more than 10 years, and more than half $(1,221(55.8 \%))$ reported having $1-2$ children. More than half $(1,145(52.3 \%))$ of the women and half $(1,129(51.6 \%))$ of the husbands had completed university education. More than half $(1,141(52.1 \%))$ of the participating women were also employed; however, the majority of women $(74.8 \%)$ were financially dependent upon their husbands. Most of the sample 
lived in urban areas $(1,641(74.9 \%))$, and more than half $(1,163$ (53.1\%)) of the women reported that their income was sufficient. About one-third of the participating women (583 (26.6\%)) had substance abusing husbands (Table 1 ).

\begin{tabular}{|c|c|}
\hline Variables & $n(\%)$ \\
\hline \begin{tabular}{|l} 
Age \\
$18-34$ \\
$35-44$ \\
$45-55$ \\
$>55$ \\
\end{tabular} & $\begin{array}{l}734(33.5) \\
1,016(46.4) \\
315(14.4) \\
125(5.7)\end{array}$ \\
\hline $\begin{array}{l}\text { Duration of marriage } \\
<5 \text { years } \\
5-10 \text { years } \\
>10 \text { years }\end{array}$ & $\begin{array}{l}424(19.4) \\
683(31.2) \\
1,083(49.5) \\
\end{array}$ \\
\hline $\begin{array}{l}\text { Consanguinity } \\
\text { yes } \\
\text { no }\end{array}$ & $\begin{array}{l}337(15.4) \\
1,853(84.6)\end{array}$ \\
\hline $\begin{array}{l}\text { Married more than once } \\
\text { yes } \\
\text { no }\end{array}$ & $\begin{array}{l}156(7.1) \\
2,034(92.9)\end{array}$ \\
\hline $\begin{array}{l}\text { Number of children } \\
\text { having no children } \\
1-2 \text { children } \\
3-4 \text { children } \\
>5 \text { children }\end{array}$ & $\begin{array}{l}115(5.3) \\
1,221(55.8) \\
802(36.6) \\
52(2.4)\end{array}$ \\
\hline $\begin{array}{l}\text { Educational level of wife } \\
\text { primary education } \\
\text { preparatory/secondary education } \\
\text { high education } \\
\text { postgraduate education }\end{array}$ & $\begin{array}{l}202(9.2) \\
707(32.3) \\
1,145(52.3) \\
136(6.2)\end{array}$ \\
\hline $\begin{array}{l}\text { Educational level of husband } \\
\text { primary education } \\
\text { preparatory/secondary education } \\
\text { high education } \\
\text { postgraduate education }\end{array}$ & $\begin{array}{l}191(8.7) \\
763(34.8) \\
1,129(51.6) \\
107(4.9)\end{array}$ \\
\hline \begin{tabular}{|l} 
Residence \\
rural \\
urban
\end{tabular} & $\begin{array}{l}549(25.1) \\
1,641(74.9)\end{array}$ \\
\hline \begin{tabular}{|c|}
$\begin{array}{c}\text { Employment status } \\
\text { employed } \\
\text { housewife }\end{array}$ \\
\end{tabular} & $\begin{array}{l}1,141(52.1) \\
1,049(47.9)\end{array}$ \\
\hline $\begin{array}{l}\text { Financially dependent upon husband } \\
\text { yes } \\
\text { no }\end{array}$ & $\begin{array}{l}1,638(74.8) \\
552(25.2) \\
\end{array}$ \\
\hline $\begin{array}{l}\text { Substance abuse by husband } \\
\text { nothing } \\
\text { smoking } \\
\text { drugs } \\
\text { alcohol }\end{array}$ & $\begin{array}{l}1,607(73.4) \\
403(18.4) \\
160(7.3) \\
20(0.9)\end{array}$ \\
\hline $\begin{array}{l}\text { Income } \\
\text { sufficient } \\
\text { not sufficient }\end{array}$ & $\begin{array}{l}1,163(53.1) \\
1,027(46.9)\end{array}$ \\
\hline $\begin{array}{l}\text { Housing type } \\
\text { rent } \\
\text { owner }\end{array}$ & $\begin{array}{l}584(26.7) \\
1,606(73.3)\end{array}$ \\
\hline
\end{tabular}

Table 2 shows that about $219(10 \%)$ of the sample women reported their general health status as bad or very bad, and 289 $(13.2 \%)$ of the women had a history of chronic diseases. More than one third $(779(35.6 \%))$ of the women suffer from depression, and a further 977 (44.6\%) had insomnia that affects their daily life (Table 2 ).

Table 3 illustrates the prevalence of domestic violence and the magnitude of each type of domestic violence against women during the COVID-19 pandemic quarantine. Out of 2,190 married Egyptian women who participated in the study, 946 (43.2\%) had experienced spousal violence during the quarantine. Of 946 study subjects experiencing domestic violence, physical abuse (80.23\%) was the most prevalent type, followed by emotional abuse (46.61\%), while $25.58 \%$ of them reported sexual abuse. The proportion of women reporting current moderate or severe suffering from their abuse was high among the women who had experienced physical abuse (759 (100\%)) compared with 335 (75.96\%) for emotional abuse and 216 (89.3\%) for sexual abuse. In terms of disclosure and assistance seeking, about two-thirds of the women did not seek assistance; moreover, more than half (499 (52.75\%)) did not disclose any abuse or sought assistance although suffering.

\begin{tabular}{|l|l|}
\hline \multicolumn{2}{|l|}{ Table 2. Clinical characteristics of the study subjects $(\boldsymbol{n}=\mathbf{2 , 1 9 0 )}$} \\
\hline Variables & $n(\%)$ \\
\hline $\begin{array}{l}\text { Self-reported health status } \\
\text { very good }\end{array}$ & $854(39.0)$ \\
good & $1,117(51.0)$ \\
bad & $201(9.2)$ \\
\hline Hery bad & $18(0.8)$ \\
$\quad$ present & \\
absent & $289(13.2)$ \\
\hline $\begin{array}{l}\text { How many times did you visit your doctor during } \\
\text { the last year? }\end{array}$ & $1,901(86.8)$ \\
$\quad$ never & \\
$1-3$ times & $344(15.7)$ \\
$4-6$ times & $1,430(65.3)$ \\
7 or more times & $259(11.8)$ \\
\hline Depression & $157(7.2)$ \\
\hline present & \\
absent & $779(35.6)$ \\
\hline Insomnia that affect your daily life & $1,411(64.4)$ \\
present & \\
absent & $977(44.6)$ \\
\hline
\end{tabular}

Table 3. Prevalence of women experienced spousal violence and the degree of current suffering during the COVID-19 pandemic quarantine in the study sample $(n=2,190)$

\begin{tabular}{|l|l|}
\hline $\begin{array}{l}\text { Domestic violence } \\
\text { present } \\
\text { absent }\end{array}$ & $n(\%)(n=2,190)$ \\
$946(43.2)$ \\
$\begin{array}{l}\text { Type of domestic violence } \\
\text { emotional abuse } \\
\text { physical abuse } \\
\text { sexual abuse }\end{array}$ & $n(\%)(n=946)$ \\
\hline $\begin{array}{l}\text { The degree of current suffering among } \\
\text { women experiencing emotional abuse } \\
\text { none }\end{array}$ & $441(46.61)$ \\
moderate suffering & $759(80.23)$ \\
severe suffering & $n(\%)(n=441)$ \\
\hline $\begin{array}{l}\text { The degree of current suffering among } \\
\text { women experiencing physical abuse } \\
\text { none } \\
\text { moderate suffering }\end{array}$ & $106(24.04)$ \\
severe suffering & $241(54.64)$ \\
\hline $\begin{array}{l}\text { The degree of current suffering among } \\
\text { women experiencing sexual abuse } \\
\text { none } \\
\text { moderate suffering }\end{array}$ & $94(21.32)$ \\
severe suffering & $n(\%)(n=759)$ \\
\hline $\begin{array}{l}\text { Seeking assistance } \\
\text { no, did not suffer } \\
\text { no, although suffering } \\
\text { yes }\end{array}$ & $367(48.35)$ \\
\hline
\end{tabular}


Table 4 demonstrates that women experienced a significant increase in the rate of domestic violence from their partners during the COVID-19 pandemic quarantine $(p<0.001)$. Women also reported a significant increase in the frequencies of all forms of domestic violence (emotional, physical and sexual abuse $(p=0.035, p<0.001, p<0.001))$ during the COVID-19 pandemic compared with the frequencies one year before the COVID-19 pandemic. The level of severity of emotional, physical and sexual abuse also showed a significant increase during the COVID-19 pandemic.

Table 5 shows a binary logistic regression analysis to ascertain the factors that are associated with domestic violence. women who were in the 18-34 years of age group score (OR $=2.05 ; 95 \% \mathrm{Cl}: 1.53-2.75 ; p<0.05)$, who had a short duration (less than 10 years) of marriage score $(\mathrm{OR}=1.58 ; 95 \% \mathrm{Cl}$ : $1.28-1.96 ; p<0.05)$, with a lower level of education score (OR $=1.80 ; 95 \% \mathrm{Cl}: 1.45-2.23 ; p<0.05)$, who have a husband with a low level of education score $(\mathrm{OR}=1.92 ; 95 \% \mathrm{Cl}$ : $1.55-2.38$; $p<0.05)$, who have a substance abusing husband score (OR = $1.57 ; 95 \% \mathrm{Cl}: 1.25-1.96 ; p<0.05)$, who live in a rural area score (OR $=1.58 ; 95 \% \mathrm{Cl}: 1.25-1.99 ; p<0.05)$, women with depression (OR $=5.20 ; 95 \% \mathrm{Cl}: 4.20-6.44 ; p<0.05)$, or had insomnia (OR $=1.38 ; 95 \% \mathrm{Cl}: 1.13-1.68 ; p<0.05)$ were more likely to experience spousal violence during COVID-19 pandemic quarantine.

Table 4. Changes in the frequencies of violence victimisation 1 year before and during the COVID-19 pandemic in the study sample
( $n=2,190)$
\begin{tabular}{|l|l|l|l|l|}
\hline Variables & $\begin{array}{l}1 \text { year before COVID-19 pan- } \\
\text { demic }(n=2,190) n(\%)\end{array}$ & $\begin{array}{l}\text { During COVID-19 } \\
\text { pandemic }(n=2,190) n(\%)\end{array}$ & Test value ${ }^{*}$ & $p$ \\
\hline Domestic violence & $610(27.9)$ & $946(43.2)$ & 315.24 & $<0.001^{*}$ \\
\hline Emotional abuse & $401(18.1)$ & $441(20.1)$ & 4.422 & 0.035 \\
\hline Mild emotional abuse & $135(6.6)$ & $47(2.1)$ & 40.75 & $<0.001^{*}$ \\
Moderate emotional abuse & $202(9.2)$ & $264(12.1)$ & 12.01 & 0.001 \\
Sever emotional abuse & $64(2.9)$ & $130(5.9)$ & 20.126 & $<0.001^{*}$ \\
\hline Physical abuse & $463(21.1)$ & $759(34.7)$ & 243.09 & $<0.001^{*}$ \\
\hline Mild physical abuse & $132(1.4)$ & $216(9.9)$ & 26.91 & $<0.001^{*}$ \\
Moderate physical abuse & $277(12.6)$ & $448(20.5)$ & 68.97 & $<0.001^{*}$ \\
Sever physical abuse & $54(2.5)$ & $95(4.3)$ & 13.26 & $<0.001^{*}$ \\
\hline Sexual abuse & $71(3.2)$ & $242(11.1)$ & 167.05 & $<0.001^{*}$ \\
\hline Mild sexual abuse & $25(1.1)$ & $69(3.2)$ & 23.71 & $<0.001^{*}$ \\
Moderate sexual abuse & $37(1.7)$ & $136(6.2)$ & 69.09 & $<0.001^{*}$ \\
Sever sexual abuse & $9(0.4)$ & $37(1.7)$ & 16.57 & $<0.001^{*}$ \\
\hline
\end{tabular}

${ }^{1}$ McNemar's test, * statistically significant at $p<0.05$.

\begin{tabular}{|c|c|c|c|c|c|c|}
\hline \multirow[t]{2}{*}{ Factors } & \multicolumn{2}{|c|}{ Domestic violence } & \multirow[t]{2}{*}{6} & \multirow[t]{2}{*}{ S.E. } & \multirow[t]{2}{*}{ Wald } & \multirow[t]{2}{*}{ OR (95\% CI) } \\
\hline & $\begin{array}{l}\text { Yes } \\
(n=946) \\
n(\%)\end{array}$ & $\begin{array}{l}\text { No } \\
(n=1,244) \\
n(\%)\end{array}$ & & & & \\
\hline Age (18-34) & $856(90.5)$ & $894(71.9)$ & 0.720 & 0.149 & 23.38 & $2.05(1.53-2.75)^{*}$ \\
\hline Duration of marriage ( $<10$ years) & $592(62.6)$ & $515(41.4)$ & 0.460 & 0.109 & 17.84 & $1.58(1.28-1.96)^{*}$ \\
\hline Consanguinity (yes) & $153(16.2)$ & $184(14.8)$ & 0.039 & 0.146 & 0.071 & $1.04(0.782-1.38)$ \\
\hline $\begin{array}{l}\text { Low educational level of wife }<12 \text { years } \\
\text { education }\end{array}$ & $532(56.2)$ & $377(30.3)$ & 0.588 & 0.110 & 28.69 & $1.80(1.45-2.23)^{*}$ \\
\hline $\begin{array}{l}\text { Low educational level of husband }<12 \\
\text { years education }\end{array}$ & $575(60.8)$ & $379(30.5)$ & 0.651 & 0.110 & 35.27 & $1.92(1.55-2.38)^{*}$ \\
\hline $\begin{array}{l}\text { Substance abuse by husband (smoking } \\
\text { - drugs - alcohol) }\end{array}$ & $335(35.4)$ & $248(19.9)$ & 0.449 & 0.115 & 15.16 & $1.57(1.25-1.96)^{*}$ \\
\hline Residence (rural) & $274(29.0)$ & $275(22.1)$ & 0.459 & 0.119 & 14.77 & $1.58(1.25-1.99)^{*}$ \\
\hline Employment status (employed) & $533(56.3)$ & $724(58.2)$ & -0.227 & 0.117 & 3.801 & $0.797(0.634-1.01)$ \\
\hline $\begin{array}{l}\text { Financially dependent upon husband } \\
\text { (yes) }\end{array}$ & $732(77.4)$ & $906(72.8)$ & 0.208 & 0.132 & 2.474 & $1.23(0.950-1.59)$ \\
\hline Income (sufficient) & $462(48.8)$ & $701(56.4)$ & 0.084 & 0.105 & 0.633 & $1.09(0.885-1.34)$ \\
\hline History of chronic diseases (present) & $276(29.2)$ & $262(21.1)$ & 0.226 & 0.121 & 3.525 & $1.25(0.990-1.59)$ \\
\hline Depression (present) & $563(59.5)$ & $216(17.4)$ & 1.649 & 0.109 & 229.6 & $5.20(4.20-6.44)^{*}$ \\
\hline Insomnia (present) & $484(51.2)$ & $493(39.6)$ & 0.320 & 0.103 & 9.653 & $1.38(1.13-1.68)^{*}$ \\
\hline
\end{tabular}

Likelihood ratio X2 $=2311.6, p$-value $=0.002$, pseudo $R^{2}=0.360$, percent $75.6 \%, *$ statistically significant at $p<0.05$. 


\section{Discussion}

The present study was designed to assess changes in spousal violence before and during the COVID-19 pandemic among Egyptian women. Since the virus is still spreading, and isolation measures are likely to be continued, we hypothesised that the pandemic will cause a negative impact on the family, leading to a catastrophic environment for domestic violence.

In the present study, among the 2,190 women who were enrolled in it, $27.9 \%$ suffered from spousal violence 1 year before the COVID-19 pandemic, and this increased to $43.2 \%$ during the COVID-19 pandemic quarantine.

During the COVID-19 pandemic quarantine, the most common type was physical abuse (34.7\%), followed by exposure to emotional and sexual abuse $(20.1 \%$ and $11.1 \%)$, respectively, while 1 year before the COVID-19 pandemic, $21.1 \%, 18.1 \%$ and $3.2 \%$ of women reported exposure to physical, emotional and sexual violence by their intimate partner, respectively.

The prevalence of domestic violence in our study was in agreement with Egypt Demographic and Health Survey report 2014 , which declared that about $30 \%$ of ever married women aged 15-49 years had experienced some form of spousal violence, and about $25 \%$ were subjected to physical violence, $19 \%$ to emotional violence and $4 \%$ to sexual violence [12]. Furthermore, many studies were carried out in Africa to study the prevalence of intimate partner violence (IPV), and they showed that $36.6 \%$ of women in Africa experienced lifetime physical and/or sexual IPV among ever partnered women [19], and about 25\% in Ethiopia and $34 \%$ in Zimbabwe experienced physical/sexual IPV [20]. Furthermore, according to WHO, 35\% of women worldwide, have experienced physical and/or sexual violence by their intimate partner [21], while population-based cross-sectional surveys conducted in four countries (Cambodia, China, Papua New Guinea (PNG) and Sri Lanka) in 2017 found that the previous-year prevalence of exposure to different types of intimate partner violence was $32.1 \%, 27.7 \%, 8.2 \%$ and $4.1 \%$ for sexual, economic, physical and emotional, respectively [22].

The low prevalence of sexual violence in our study could be explained in light of the fact that it is more difficult for women to disclose experiences of sexual violence than physical violence, and this could be attributed to their culture, religion and traditions.

The prevalence of domestic violence in our study disagreed with the results of a cross-sectional study that had been conducted by El-Nimr et al. among 657 women in a slum area in Helwan, Cairo, Egypt, in 2018, which found that the prevalence of women exposed to partner violence was $59.1 \%$. Among them, $49.1 \%, 37.3 \%$ and $6.4 \%$ reported exposure to psychological, physical and sexual violence, respectively [23].

The discrepancy in research findings could be explained by the difference in research methodology, as El-Nimr et al. studied different forms of violence (physical, psychological or sexual) during the previous 12 months and their frequency and the relation with the perpetrator(s), either an intimate or non-intimate partner.

Our results were inconsistent with the findings of Mamdouh et al., who conducted a cross-sectional survey among 3,271 ever married women attending 12 randomly selected family health centres in Alexandria, Egypt. They reported that more than three quarters of the participants $(77 \%)$ reported experiencing spousal violence during their marital life, and the most common type reported was emotional violence ( $71 \%)$, followed by physical and sexual (50.3\%, 37.1\%, respectively) [24].

The difference in the prevalence figures could be attributed to methodological differences, in which the participants in the previous study were asked about experiencing spousal violence during their marital life, not as in our study of 1 year before and during the COVID-19 pandemic quarantine.

Many reports were consistent with our results regarding the prevalence of domestic violence during the COVID-19 pandemic quarantine. One of them, originating from local police near the epicentre of the COVID-19 outbreak in China's Hubei province, indicated that DV tripled during February 2020 compared to February 2019 [25]. According to the United Nations entity UN Women, DV reports in France have also increased (30\%) since they initiated a lockdown on 17 March. Reports of DV in Argentina have increased $25 \%$ since their lockdown on 20 March [26]. The organisation also reports a $30 \%$ increase in helpline calls in Cyprus and a 33\% increase in Singapore [26].

The increase in the prevalence of spousal violence during the COVID-19 pandemic quarantine can be explained as a result of social isolation, widespread organisational closures, which is likely to be continued for an extended period of time, stress, unemployment, reduced income, sudden shifts in daily routines, limited social support and alcohol abuse, which are likely to be risk factors for family violence, and more women have been subjected to different forms of partner violence.

In the current study, the results of the help-seeking behaviour of women in response to their exposure to violence were different; among 946 women exposed to partner violence, only 315 (33.29\%) asked for help.

This result was consistent with the finding of El-Nimr et al., who found that, concerning health care-seeking behaviour, nearly two thirds (66.2\%) of women exposed to IPV reported that they had never asked for health care upon exposure to violence, $31.2 \%$ reported that they sometimes sought health care, while only $2.6 \%$ reported that they always ask for health care upon exposure to violence [23].

Not asking for help in our study could be explained by the fact that some of them did not feel that they were in danger or did not suffered from violence, in addition to their fear that this will badly affect their children. The Egyptian culture also stresses family loyalty and dignity. Disclosing domestic violence to a physician may be inappropriate and is perceived as a form of family disrespect.

In the current study, a binary logistic regression analysis was used to determine the characteristics of women who experienced violence and the contexts in which they lived, which showed that younger age (18-34 years old), duration of marriage less than 10 years, educational level less than 12 years for both wife and husband, substance abuse by husband (smoking, drugs or alcohol), rural residence and suffering from insomnia or depression were significantly associated with domestic violence, while positive consanguinity, employment status, financially depending upon the husband, income or suffering from chronic disease were insignificantly associated with domestic violence.

These findings were consistent with the findings of the study that was conducted by Mamdouh et al., who found that a low educational attainment of the husbands, the husbands' habits, such as smoking and drug use, the husbands' psychological status and a history of exposure to physical violence during adolescence were correlated with spousal violence among the participants in their survey [24]. Furthermore, many studies agreed with the current findings that there was significant association of violence with the younger age of women, lower literacy status, shorter duration of marriage and women having no children [27].

A multi-country study report by the WHO in 2011 analysed various factors associated with recent intimate partner violence among women. They reported secondary education, high socioeconomic status and formal marriage as protective measures against domestic violence. Whereas, on the other hand, alcohol abuse, cohabitation and young age were reported as factors associated with an increased risk of the same. The risk becomes doubled when the factors were reported in both women and the partner [28]. Studies conducted in other countries, such as Bangladesh and Egypt, reported similar determinants for domestic violence, such as young age, illiteracy/lower education, low income and a positive history of family conflicts [29]. 
Our findings were inconsistent with the finding of Field et al., who found that the likelihood of the occurrence of IPV was 2.6 times more likely among women who were unmarried compared to married women, which was supported by the findings from South Africa and the Demographic and Health Survey in sub-Saharan African countries [30]. El-Nimr et al. found that there were no significant associations between exposure to violence and age, education or marital status [23]. This difference can be explained by methodological differences among the cited literature, such as variation in the characteristics of participants or the data collection methods.

Many studies reported that illiteracy among women was associated with domestic violence, and more than half of the married women in this rural study setting experienced one or more forms of violence. On the other hand, the husband's education was not found to be significantly associated with violence [27]. This can be explained as women's education having a safeguarding effect on their acceptance of violence, because education increases autonomy, as well as social and economic empowerment. Regarding residence, women who participated in the study from rural residences may not have had access to different information that deals with gender equality, women's right and violence reduction strategies.

\section{Limitations of the study}

There may be some possible limitations in this study, for example, sampling bias, where the selected participants may not represent the real population under study, and this can af- fect the generalisation of the results, as due to social isolation, an online questionnaire had to be used in this study, and thus our study included women who had access to social media and were educated. However, we cannot generalise the results for less educated, illiterate and very poor women. Another limitation is the recall period of 12 months, which is lengthy and is susceptible to underreporting, especially on issues of verbal violence. Finally, the sensitivity of the questions in the questionnaire regarding sexual abuse is another limitation, because it addresses sensitive issues, making it underreported.

\section{Conclusions}

Measures to stop the spread of COVID-19, such as social isolation, travel restrictions and stay-at-home, are dramatically increasing the prevalence of domestic violence in Egypt in comparison to its prevalence 1 year before the pandemic. Age, duration of marriage, educational status of subjects and their spouses, residence, spousal substance abuse, depression and insomnia were reported as significant predictors of domestic violence among Egyptian women. Identification of victims of domestic violence and offering them help is an important matter and should be implemented at the level of primary health care centres through a multidisciplinary team, which should include mental health professionals, family physicians and professional social workers to address this issue effectively.

Acknowledgements. The authors would like to acknowledge all the participants for their co-operation.

Source of funding: This work was funded from the authors' own resources.

Conflicts of interest: The authors declare no conflicts of interest.

\section{References}

1. Centers for Disease Control and Prevention. Cases of coronavirus disease (COVID-19) in the U.S. U.S. Department of Health \& Human Services [cited 18.04.2020]. Available from URL: https://www.cdc. gov/coronavirus/2019-ncov/cases-updates/cases-in-us.html.

2. Huang C, Wang Y, Li X, et al. Clinical features of patients infected with 2019 novel coronavirus in Wuhan, China. Lancet 2020; 395(10223): 497-506, doi: 10.1016/s0140-6736(20)30183-5.

3. World Health Organization. Director-General's opening remarks at the media briefing on COVID-19 [cited 11.03.2020]. Available from URL: https://www.who.int/dg/speeches/detail/who-director-general-s-opening-remarks-at-the-media-briefing-on-covid-19-11march-2020.

4. Parmet WE, Sinha MS. Covid-19 - the law and limits of quarantine. N Engl J Med 2020; 382(15): e28.

5. United States Bureau of Labor Statistics. Labor force statistics from the current population survey; 2020 [cited: 18.04.2020]. Available from URL: https://www.bls.gov/cps/cps_over.htm.

6. Brooks SK, Webster RK, Smith LE, et al. The psychological impact of quarantine and how to reduce it: rapid review of the evidence. Lancet 2020; 395(10227): 912-920, doi: 10.1016/S0140-6736(20)30460-8.

7. Catalá-Miñana A, Lila M, Oliver A, et al. Contextual factors related to alcohol abuse among intimate partner violence offenders. Subst Use Misuse 2017; 52(3): 294-302, doi: 10.1080/ 10826084.2016.1225097.

8. Devries KM, Mak JYT, García-Moreno C, et al. The global prevalence of intimate partner violence against women. Science 2013; 340(6140): 1527-1528, doi: 10.1126/science.1240937.

9. Hawcroft C, Hughes R, Shaheen A, et al. Prevalence and health outcomes of domestic violence amongst clinical populations in Arab countries: a systematic review and meta-analysis. BMC Public Health 2019; 19(1): 315, doi: 10.1186/s12889-019-6619-2.

10. World Health Organisation. World Report on Violence and Health [cited: 12.04.2019]. Available from URL: http://www.who.int/violence_injury_prevention/viol ence/world_report/en/.

11. Abrahams N, Devries K, Pallitto C, et al. Global and regional estimates of violence against women: prevalence and health effects of intimate partner violence and non-partner sexual violence. Geneva: World Health Organization; 2013.

12. Ministry of Health and Population [Egypt], El-Zanaty and Associates [Egypt], and ICF International. Egypt demographic and health survey. Cairo, Egypt and Rockville, Maryland, USA: Ministry of Health and Population and ICF International; 2014.

13. Douki S, Nacef F, Belhadj A, et al. Violence against women in Arab and Islamic countries. Arch Womens Ment Health 2003; 6(3): 165-171, doi: 10.1007/s00737-003-0170-x.

14. Pallitto C, García-Moreno C, Jansen H, et al. Intimate partner violence, abortion, and unintended pregnancy: results from the who multicountry study on women's health and domestic violence. Int J Gynaecol Obstet 2013; 120(1): 3-9, doi: 10.1016/j.ijgo.2012.07.003.

15. Abu-Ras WM. Cultural beliefs and service utilization by battered Arab immigrant women. Violence Against Women 2007; 13(10): 1002-1028, doi: 10.1177/1077801207306019.

16. Raj A, Silverman J. Violence against immigrant women: the roles of culture, context, and legal immigrant status on intimate partner violence. Violence Against Women 2002; 8(3): 367-398, doi: 10.1177/10778010222183107.

17. Swahnberg IM, Wijma B. The NorVold Abuse Questionnaire (NorAQ): validation of new measures of emotional, physical, and sexual abuse, and abuse in the health care system among women. Eur J Public Health 2003; 13: 361-366. 
18. Haddad LG, Shotar A, Younger JB, et al. Screening for domestic violence in Jordan: validation of an Arabic version of domestic violence against women questionnaire. Int J Womens Health 2011; 3: 79.

19. World Health Organization, Global and Regional Estimates of Violence against Women. Prevalence and health effects of intimate partner violence and non-partner sexual violence, reproductive health and research. Geneva: WHO; 2013. Available from URL: http://apps who.int/iris/bitstream/10665/85240/1/9789241548595_eng.

20. Rurangirwa AA, Mogren I, Ntaganira J, et al. Intimate partner violence among pregnant women in Rwanda, its associated risk factors and relationship to ANC services attendance: a population-based study. BMJ Open 2017; 7(2): e013155.

21. World Health Organization. Global status report on violence prevention 2014. Geneva: World Health Organization; 2014. Available from URL: http://www.who.int/violence_injury_prevention/violence/ status_report/2014/en/.

22. Jewkes R, Fulu E, Tabassam Naved R, et al. Women's and men's reports of past-year prevalence of intimate partner violence and rape and women's risk factors for intimate partner violence: a multicountry cross-sectional study in Asia and the Pacific. PLOS MED 2017; 14(9): e1002381, doi: 10.1371/journal. pmed.1002381.

23. El-Nimr NA, Gouda SM, Helmy Wahdan IM. Violence against women in a slum area in Helwan, Cairo, Egypt: a community based survey. J Res Health Sci 2020; 20(1): e00466.

24. Mamdouh HM, Ismail HM, Kharboush IF, et al. Prevalence and risk factors for spousal violence among women attending health care centers in Alexandria, Egypt. East Mediterr Health J 2012; 18(11): 1118-1126, doi: 10.26719/2012.18.11.1118.

25. Fraser E. Impact of COVID-19 pandemic on violence against women and girls. Development UAft2020; https://www.girlsnotbrides.org/ resource-centre/impact-of-covid-19-pandemic-on-violence-against-women-and-girls/.

26. UN Women. COVID-19 and ending violence against women and girls; Gender-Based Violence 2020; https://digitalcommons.wcl.american.edu/wlpviolence/1.

27. George J, Nair D, Premkumar NR, et al. The prevalence of domestic violence and its associated factors among married women in a rural area of Puducherry, South India. J Family Med Prim Care 2016; 5(3): 672-676.

28. Abramsky T, Watts $\mathrm{CH}$, GarciaMoreno $\mathrm{C}$, et al. What factors are associated with recent intimate partner violence? Findings from the WHO multicountry study on women's health and domestic violence. BMC Public Health 2011; 11: 109.

29. Fahmy HH, Rahman AE. Determinants and health consequences of domestic violence among women in reproductive age at Zagazig District, Egypt. J Egypt Public Health Assoc 2008; 83: 87-106.

30. Field $\mathrm{S}$, Onah $\mathrm{M}$, Heyningen $\mathrm{T}$ van, et al. Domestic and intimate partner violence among pregnant women in a low resource setting in South Africa. BMC Women's Health 2018; 18(1): 1-13.

Tables: 5

Figures: 0

References: 30

Received: 24.07.2020

Reviewed: 04.08.2020

Accepted: 27.08.2020

Address for correspondence:

Eman Esmat Tosson, MD

Department of Family Medicine

Faculty of Medicine

Suez Canal University

Ismailia

Egypt

Tel.: +20 1222901991

E-mail:dr.eman_tosson@hotmail.com 